\title{
Significant differences in denudation rates of mountainous small watersheds in eastern margin of Tibet plateau.
}

LIFENG CUI $^{1 *}$, SHENG XU ${ }^{1}$, CONGQIANG LiU ${ }^{1}$, ZHIQI ZHAO ${ }^{2}$, XIAOLONG ZHANG ${ }^{1}$

${ }^{1}$ Institute of Surface-Earth System Science, Tianjin University, Tianjin.China

(*Correspondence: lifeng.cui@tju.edu.cn)

${ }^{2}$ School of Earth Science and Resources, Chang'An

University, Xi'an, China

We systematically collected 16 sediment samples from small watersheds in Nanya River, which is the tributary of Dadu river and located in eastern margin of Tibet plateau. The local climate is subtropical monsoon. the MAP and MAT are $795 \mathrm{~mm}$ and $16.9{ }^{\circ} \mathrm{C}$ at estuary, respectively. The main stream extend $71.8 \mathrm{~km}$ and yield a $3470 \mathrm{~m}$ relative relief, Thus, the climate change obviously with vertical gradient.

Sediment from granitic watersheds with different areas were collected and pretreated to get pure quartz with physical and chemical methods. After extraction of beryllium element, ${ }^{10} \mathrm{Be} /{ }^{9} \mathrm{Be}$ ratios were analyzed in Institute of Surface-Earth System Science, Tianjin University.

According to CRONUS-Earth online calculators, there are significant differences among denudation rates in these small granitic basins. The results revealed large differences between high and low denudation rates, often by three order of magnitude. Through analysis, we contribute the huge variance to the consequence of short-term frequent geologic disasters, for instance, landslide and debris flow, which export fresh material from small watershed to main stream and dilute ${ }^{10} \mathrm{Be}$ concentration. 